\title{
Post Tonsillectomy Pain of Bipolar Electrocautery and Coldsteel Dissection: A Randomized Prospective Comparative Study
}

\author{
Abdullah R. Y. Alkhalil ${ }^{1}$, Shilan Mostafa Mohammad ${ }^{1}$, Omer Q. B. Allela ${ }^{2 *}$ \\ ${ }^{I}$ College of Medicine, University of Duhok, Duhok-Kurdistan Region, IRAQ. \\ ${ }^{2}$ College of Pharmacy, University of Duhok, Duhok-Kurdistan Region, IRAQ.
}

Received: 16 March 2018;

Accepted: 27 May 2018

*Correspondence to:

Dr. Omer Q. B. Allela, PhD,

Assistant Professor in Clinical Pharmacy

College of Pharmacy, University of Duhok,

Duhok-Kurdistan Region, IRAQ.

Phone no: 009647717494296

Email: omarallela@yahoo.com

Copyright: (1) the author(s),publisher and licensee Indian Academy of Pharmacists. This is an open-access article distributed under the terms of the Creative Commons Attribution Non-Commercial License, which permits unrestricted non-commercial use, distribution, and reproduction in any medium, provided the original work is properly cited.

\begin{abstract}
Backgrounds and objectives: Tonsillectomy is regarded as one of the most common surgical operation carried out by otolaryngologists worldwide. Pain is one of the most common troubling problems both the patients and surgeons have to face postoperatively. The study aim is to compare pain scores after surgeries between bipolar diathermy and cold steel techniques. Patients and methods: This is a comparative prospective study conducted at Azadi Teaching hospital - Department of otolaryngology - Head and neck surgery in DuhokKurdistan Region / Iraq, from September 2016 to February 2017. 40 patients have been included in this study and they randomly selected into two groups, group A (20 patients) underwent tonsillectomy by cold steel method and group B (20 patients) by diathermy method. Results: Data reveled that there was non-significant difference in pain between the two groups in the day of surgery and ${ }^{\text {st }}$ postoperative day. Pain score have significantly became different in day 2 and day 3 postoperatively $(p=0.01, p=0.002)$ respectively, which mandate the addition of Non-steroidal anti-inflammatory drugs to restore the pain difference to be non-significant again. Pain outcome is more common in patients with recurrent tonsillitis regardless of type of surgery. Conclusion: Bipolar diathermy tonsillectomies is considered a good alternative procedure for the old cold steel technique with insignificant difference in pain scores especially after the addition of Non-steroidal anti-inflammatory drugs with no recorded bleeding issues.
\end{abstract}

Keyword: Tonsillectomy, Pain, Duhok, Iraq

\section{INTRODUCTION}

Tonsillectomy is regarded as one of the most common surgical operation carried out by otolaryngologists worldwide..$^{[1]}$ As pain is considered the main problem in most tonsillectomy patients, different surgical techniques have been used in the search for safe and effective post tonsillectomy pain relief. However the results have been disagreeing and still controversial. ${ }^{[1]}$

There are multiple techniques used for tonsillectomy and the use of this techniques is mainly depend on surgeon preference and experience, these techniques include the traditional cold steel "Cold Method" and the "Hot Methods" procedures including bipolar diathermy, harmonic scalpel, coblation and monopolar cautery. ${ }^{[2]}$ Due to high intraoperative blood loss cold steel techniques have been infrequently used in United States. ${ }^{\left[{ }^{[3]}\right.}$ Instead electrocautery methods have been associated with less intraoperative bleeding and quicker time of surgery. ${ }^{[4]}$ While having these advantages there have been some concerned raised about the increase of postoperative morbidity of electrocautery methods including: pain and bleeding. ${ }^{[5]}$

Pain is considered the most common postoperative problem and it can lead to poor oral intake, dehydration and significant dysphagia, and it is one of the main cause that brought patient for clinical counseling. ${ }^{[6]}$ Tonsillectomy is mainly performed for pediatrics age group and as children cannot express their pain verbally, therefore, a specific tools should be used to assess the pain precisely. ${ }^{[7]}$

The purpose of this research is compare the pain "using accurate pain assessment scale" between the cold steel and bipolar electrocautery diathermy in children underwent tonsillectomy.

\section{PATIENTS AND METHODS}

After obtaining agreement from the ethics committee and written informed consent from the patients, a prospective study of 40 patients randomly selected and divided into two equal groups; group A (20 patients) who underwent elective bilateral tonsillectomy by cold steel method and group B (20 patients ) by bipolar diathermy method was conducted over a period of six months at Azadi Teaching Hospital /Duhok-Iraq, Department of Otolaryngology to evaluate the post-operative pain between the two methods of tonsillectomy, the cold steel and the bipolar diathermy technique.

Patients included in the study are patients with recurrent acute tonsillitis and patient with obstructive sleep apnea with ages between (6-15) years.

Exclusion criteria were; informed consent refusal, bleeding tendency and acute infection.

Preoperatively patients had routine hematological investigation (CBC and clotting profile) that should be within normal ranges. Patient should be admitted in the early morning at the day of surgery and fasting for at least $6 \mathrm{~h}$.

All patients were operated under general anesthesia with endotracheal intubation. All patients have a standard anesthetic given by a specialist anesthesiologist. The diathermy dissection tonsillectomy was performed using a guarded-point electrode handle with foot-controlled cutting and coagulation switches attached to a diathermy machine. Dissection was performed in coagulation mode to divide the attachments of the tonsil to the tonsillar bed close to the tonsil at 40 Watts. Great care was exercised to ensure 
minimal contact between the diathermy needle and the tonsil bed to reduce unnecessary charring. Vessels visualized were cauterized before division.

The tonsil was separated from the lower pole and the posterior tonsillar pillar with the diathermy dissector. Minimal hemorrhage was noted in most cases, but a tonsil swab was left in bed while the other tonsil was being removed. A diathermy coagulation forceps at $30 \mathrm{~W}$ was used to coagulate any significant bleeding points in the tonsillar fossa; this was not usually necessary.

Tonsillectomy in the cold dissection group was performed by incising the mucosa of anterior tonsillar pillar with the pointed end of a GwynneEvans tonsillar dissector. The tonsil was then dissected from the fossa with the blunt end. By Negus forceps, the lower pole of the tonsil was clamped then excision of the tonsil done after that we ligate the tonsil with $1 / 0$ silk suture. A swab was placed in the fossa and the other tonsil in the same way removed. The swabs were removed in the order in which they were placed; Bleeding points in the tonsillar fossae were controlled by ligature technique.

Postoperatively patients were observed in the ENT department at Azadi teaching Hospital $4 \mathrm{~h}$ postoperatively for the assessment of bleeding, airway, nausea and vomiting. Early oral intake were encouraged, most of them resumed early oral feeding starting with ice cold food then semisolid food. They were given antibiotics in the form of amoxiclave for those not allergic to Penicillin, and analgesia in the form of acetaminophen alone in the zero, first and second days post-operative day and acetaminophen plus Ibuprofen in the third day and on.

Criteria for discharge included those patients who resumed early oral intake, those without bleeding, those with stable vital signs ,those living within 20 min distance from hospital and those whose parents were educated enough to be aware of any complication occurring after discharge.

After discharge from hospital, a pain questionnaire was given to record the level of pain. Using Wong-Baker faces pain rating scale (Figure 1) which is recommended in assessing pain in children older than 3 years old, patients have been observed on day 1,2,3, after one week and after two weeks, and pain has been assessed at rest and during swallowing a piece of bread. A numerical grading from 0 to 10 using the above scale has been documented on pain questionnaires which have already been designed for this purpose.

The Wong-Baker faces pain scale used self-report of pain to assess a patient's experience of pain. It can be used in children aged between 3 and 18 years of age, depending upon their cognitive ability. ${ }^{[8]}$

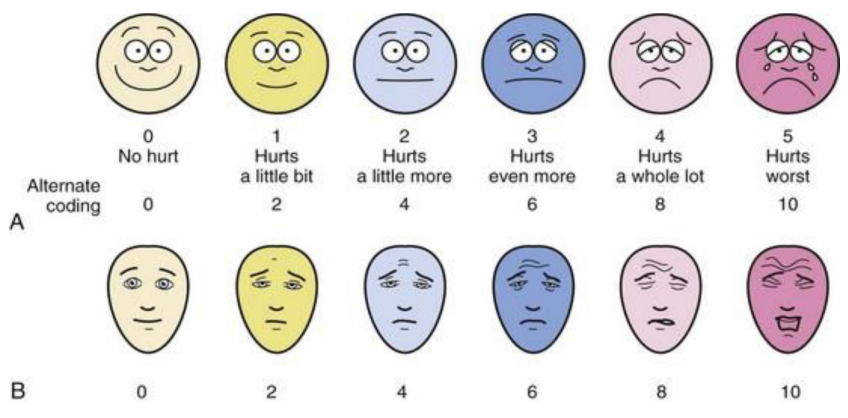

Figure 1: Wong-Baker Faces Pain Rating Scale.
Each face helps us understand how much pain the child has, and how this makes them feel. Face 0 is very happy because he doesn't hurt at all (i.e. has no pain). Face 2 hurts just a little bit. Face 4 hurts a little more. Face 6 hurts even more. Face 8 hurts a whole lot. Face 10 hurts as much as you can imagine, although you don't have to be crying to feel this bad, and the score were recorded according to these faces.

The results were analyzed using SPSS version 20 for Microsoft pack to manage and analyze the data included in the study. Fisher exact tests were used to calculate the $\mathrm{P}$-value, value of $<0.05$ considered significant.

\section{RESULTS}

There were $24(60 \%)$ males and $16(40 \%)$ females aged from 6 to 15 years with mean age of (8.13) years and a median age (10 years). $26(65 \%)$ patients were their tonsils removed due to recurrent acute tonsillitis and the other 14 $(35 \%)$ due to obstructive sleep apnea. There were no significant differences in the distribution of the age and gender of the patient.

Pain score between group A cold steel and group B diathermy was not significant in the day of surgery and first postoperative, but the pain became significant in $2^{\text {nd }}$ and $3^{\text {rd }}$ postoperative day $(p=0.01, p=0.002)$ Respectively. This mandate the addition of NSAID form $2^{\text {nd }}$ postoperative day and on (Table 1). As it is seen after the addition of NSAID the pain difference return to be not significant in $1^{\text {st }}$ and $2^{\text {nd }}$ week postoperatively. According to our study the postoperative pain is also affected by whether the surgery was performed for recurrent tonsillitis or for obstructive sleep apnea. Regardless of which type of surgery performed patient with recurrent acute tonsillitis will experience more pain than patient with obstructive sleep apnea (Table 2).

\begin{tabular}{|c|c|c|c|}
\hline & $\begin{array}{l}\text { Group A cold steel } \\
(n=20)(\text { mean } \pm S D)\end{array}$ & $\begin{array}{l}\text { Group B } \\
\text { diathermy }(n=20) \\
\text { (mean } \pm S D)\end{array}$ & P-value \\
\hline day 0 & $8.3 \pm 0.47$ & $8.37 \pm 0.5$ & NS \\
\hline 1 & $7.9 \pm 0.31$ & $8 \pm 0$ & NS \\
\hline 2 & $6.95 \pm 0.22$ & $7.95 \pm 0.23$ & 0.01 \\
\hline 3 & $6.7 \pm 0.47$ & $7.05 \pm 0.23$ & 0.002 \\
\hline $1^{\text {st }}$ week & $3.1 \pm 0.52$ & $3.37 \pm 0.5$ & NS \\
\hline $2^{\text {nd }}$ week & $1.5 \pm 0.47$ & $1.7 \pm 0$ & NS \\
\hline
\end{tabular}

NS- not significant

\begin{tabular}{|c|c|c|c|}
\hline & $\begin{array}{l}\text { Group A } \\
\text { obstructive }(n=14) \\
\text { (mean } \pm S D)\end{array}$ & $\begin{array}{l}\text { group B recurrent } \\
\text { infection }(n=26) \\
\text { (mean } \pm S D)\end{array}$ & P-value \\
\hline day 0 & $8.21 \pm 0.43$ & $8.4 \pm 0.5$ & 0.16 \\
\hline 1 & $7.85 \pm 0.36$ & $8 \pm 0$ & 0.056 \\
\hline 2 & $7.29 \pm 0.47$ & $7.52 \pm 0.59$ & 0.404 \\
\hline 3 & $6.71 \pm 0.47$ & $6.96 \pm 0.35$ & 0.095 \\
\hline 1st week & $2.64 \pm 0.84$ & $2.84 \pm 0.75$ & 0.469 \\
\hline 2nd week & $0.58 \pm 0.51$ & $0.72 \pm 0.46$ & 0.35 \\
\hline
\end{tabular}




\section{Alkhalil, et al.: Tonsillectomy Pain Post-Operative in Iraq}

There was no primary or secondary postoperative hemorrhage in both groups during the study period.

\section{DISCUSSION}

Tonsillectomy is a commonly used procedure with relatively low risks and over time multiple techniques have been used in the search to reduce postoperative complication and morbidity like pain, hemorrhage and dysphagia. However, until now no technique has proved to be superior over others and the results are still contradictory. ${ }^{[9]}$ Cold dissection tonsillectomy till date is the most commonly used technique in Iraq, and most of the published papers are talking around this technique. ${ }^{[10-11]}$ However, over the last few years we have started to use the bipolar electrocautery in our department in Duhok. Using the electrocautery to remove tonsils has been the most public method in the United States since 1930. The monopolar and bipolar electrocautery may be used for tonsillectomy. Yet, the bipolar electrocautery transfers to a smaller part of the tissue. Therefore, the spread of heat to the tissue and its environment is less. It was believed that cold dissection was favored to other methods because of more protection and less damage to surrounding tissue which leads to fast recovery and less pain in the mechanical method. In contrast, tissue damage and heating injury of the electrocautery causes delay in epithelization of tonsillar bed and may leads to more postoperative pain. ${ }^{[12-14]}$

According to Table 1. There was no significant difference in pain score between classical dissection and diathermy in day zero and day one postoperatively. Firstly; because in diathermy penetration of local tissue energy is not high enough to cause pain and, secondly; diathermy requires less stretching and trauma of muscle fiber in the tonsillar bed, while the difference started to appear in day two and on where the pain score little bit became more than that of the cold steel method due to the formation of scar which usually starts after the second day. ${ }^{[15]}$ This sequential variation in pain severity has also been labeled after various study of electro dissection tonsillectomy. Tay matched electro dissection tonsillectomy with the cold dissection and ligation technique, patients sensed less pain on the first postoperative day but more pain at the end of the first and the second week on the electro dissection side, this clinically necessate more analgesia at day two and on. ${ }^{[16]}$ On the other hand patients experience more pain in electrocautery in a study conducted by Kirazli, ${ }^{[17]}$ but differ from Kousha ${ }^{[18]}$ where pain was more in classical dissection method. Equal pain was perceived in a study by Raut with significant less time and intraoperative blood loss with diathermy technique (13).

In our study, pain was significantly more in patients have tonsillectomy for recurrent tonsillitis regardless of which technique was adapted for removal (Table 2); this could be explained because the dissection of the tonsils from the surrounding scared tissue could have been associated with great intraoperative trauma which may lead to more oropharyngeal muscles stretching with subsequent spasm and pain. Our results was different from Zagolski when he found that postoperative pain was less with patient with recurrent tonsillitis, although, he stated that it shoul be more logically and he reasoned that because he used different techniques for removal of the tonsils. ${ }^{[19]}$

\section{CONCLUSION AND RECOMMENDATION}

Diathermy technique considered as a safe procedure and it is associated with similar scores of pain in comparison with the classical cold steel technique in the first two post-operative days, however, it mandate the addition of one of the Non-steroidal anti- Inflammatory drugs from day three and on with no additional risks. We find the pain outcome is also dependent on type of indication of tonsillectomy and it was more with patient with recurrent tonsillitis.

Based on that conclusion we recommend the adoption of diathermy technique in tonsillectomy as an-alternative procedure to the classic cold steel technique.

\section{CONFLICT OF INTEREST}

Nil

\section{REFERENCES}

1. Akural E, Koivunen P, Teppo H, Alahuhta S, Löppönen H. Post-tonsillectomy pain: A prospective, randomised and double-blinded study to compare an ultrasonically activated scalpel technique with the blunt dissection technique. Anaesthesia. 2001;56(11):1045-50.

2. Arbin L, Enlund M, Knutsson J. Post-tonsillectomy pain after using bipolar diathermy scissors or the harmonic scalpel: A randomised blinded study. European Archives of Oto-Rhino-Laryngology. 2017;274(5):2281-5.

3. Spektor Z, Kay DJ, Mandell DL. Prospective comparative study of pulsedelectron avalanche knife (PEAK) and bipolar radiofrequency ablation (coblation) pediatric tonsillectomy and adenoidectomy. American J otolaryngology. 2016;37(6):528-33.

4. Sharma K, Kumar D. Ligation versus bipolar diathermy for hemostasis in tonsillectomy: A comparative study. Indian Journal of Otolaryngology and Head and Neck Surgery. 2011;63(1):15-9.

5. Mann DG, et al. Tonsillectomy-some like it hot. The Laryngoscope. 1984;94(5):677-9.

6. Thung AK, et al. Double-Blind Randomized Placebo-Controlled Trial of SingleDose Intravenous Acetaminophen for Pain Associated With Adenotonsillectomy in Pediatric Patients With Sleep-Disordered Breathing. The Journal of Pediatric Pharmacology and Therapeutics. 2017;22(5):344-51.

7. Soleymanifard F, Khademolhoseyni SM, Nouri JM. Nursing Process in Post Tonsillectomy Pain Diagnosis: A Systematic Review. Global J health Sci. 2015;7(1):180.

8. Garra G, et al. Validation of the Wong Baker FACES pain rating scale in pediatric emergency department patients. Academic Emergency Medicine. 2010;17(1):50-4.

9. Brkic F, et al. Haemorrhage Rates After Two Commonly Used Tonsillectomy Methods: A Multicenter Study. Medical Archives. 2017;71(2):119.

10. Al-Abbasi AM, Saeed ZK. Hydrogen Peroxide 3\%: Is it Beneficial in Tonsillectomy? Sultan Qaboos University Med J. 2008;8(2):201.

11. Al-Juboori A. Safety of Cold Tonsillectomy Techniques: Comparison between Wired Snare and Inferior Tonsillar Pole Ligation Methods. Inter J Otorhinolaryngology. 2016;3(1):4.

12. Dyleski R, Dennis M. Tonsillitis, tonsillectomy and adenoidectomy. Atlas of Head and Neck Surgery-Otolaryngology. 2nd ed. Lippincott Williams and Wilkins. 2001:979-93.

13. Paradise JL. Tonsillectomy and adenoidectomy. Pediatric otolaryngology. 1996;2:1054-65.

14. Raut V, et al. Bipolar Scissors versus Cold Dissection Tonsillectomy: A Prospective, Randomized, Multi $\square$ Unit Study. The laryngoscope. 2001;111(12):2178-82.

15. Stuck BA, et al. Die Tonsillektomie im Kindesalter. Dtsch Arztebl.2008; 105(49):852-861.

16. Tay H. Post-operative morbidity in electrodissection tonsillectomy. The Journal of Laryngology and Otology.1995;109(3):209-11.

17. Kirazli T, et al. Bipolar electrodissection tonsillectomy in children. European Archives of Oto-Rhino-Laryngology and Head and Neck. 2005;262(9):716-8.

18. Kousha A, Banan R, Fotoohi N, Banan R. Cold dissection versus bipolar electrocautery tonsillectomy. J Res Med Sci. 2007;12(3):117-20.

19. Zagólski O, et al. Adult tonsillectomy: Postoperative pain depends on indications. Brazilian J otorhinolaryngol. 2016;82(5):589-95. 